\title{
Coordinating collaborative writing in an online environment
}

\section{Minna Nykopp ${ }^{1}$ (D) Miika Marttunen ${ }^{1} \cdot$ Gijsbert Erkens $^{2}$}

Published online: 22 November 2018

(C) The Author(s) 2018

\begin{abstract}
This study investigated how university students $(n=28)$ coordinated their collaborative online writing and what kinds of coordination profiles were found among the students. Further, the study examined the quality of the essays produced by groups of students varying in their combinations of coordination profiles. Students' written comments on their writing processes $(n=583)$ were divided into episodes focusing on coordination. Eight different categories of collaborative activities during online collaboration were found. The students' joint essays $(n=9)$ were evaluated as high, moderate and low according to the number of topics, key concepts, and integration of Internet sources in the essays. Coordination profiles were identified by K-means cluster analysis. The students mainly coordinated their collaborative writing through text-related activities, task-related activities as well as social activities. Four distinct coordination profiles were found, showing that the students coordinated their collaborative writing process in different ways. Technical problems seemed to have a negative effect on essay quality.
\end{abstract}

Keywords Collaborative writing · Coordination · Online environment · Coordination profiles

Minna Nykopp

minna.e.nykopp@jyu.fi

Miika Marttunen

miika.marttunen@jyu.fi

Gijsbert Erkens

G.Erkens@uu.nl

1 Department of Education, University of Jyväskylä, Ruusupuisto, Building RUU, Alvar Aallon katu 9, PO Box 35, 40014 Jyväskylä, Finland

2 Department of Education, Utrecht University, Heidelberglaan 1, 3584 CS Utrecht, The Netherlands 


\section{Introduction}

The rapid growth of online technologies and environments has created new possibilities to construct knowledge through interaction during the writing process. Although online environments provide many opportunities for collaborative writing, they increase the complexity of writing when compared with collaborative writing in a face to face learning situation (Lowry and Nunamaker 2003). In online situations, participants are not present in the same way as they are when working face to face; this may present challenges for combining the contributions of several individuals. Under this more complex condition, coordination activities and the different ways participants engage in coordination during collaborative writing are crucial to achieving the best conceivable outcome of the writing task.

This study focused on how university students coordinated collaborative writing in an asynchronous online environment and what coordination profiles students show when engaged in a collaborative online writing task. The study also explored the quality of the essays produced by groups of students with diverse coordination profiles.

\section{Collaborative writing in an online environment}

Giroud (1999) defines collaborative writing as a learning task in which students in small groups construct and write a text together. They participate equally in the production of the text, and are equally responsible for accomplishing the writing task by exchanging ideas, plans and suggestions for the composition of the joint text and together solving the problems that arise during writing. To reach their common goals, collaborating writers need to be mutually dependent on the information, resources, tools and cooperative intention of their partners (Erkens et al. 2005).

Online environments offer many benefits for collaborative writing, including equal participation despite differences in time and space (Alexander 2006; Parker and Chao 2007), a platform for peer reviewing (Alexander 2006), creation of documents by utilizing information from different sources (Murugesan 2007), use of tools enabling flexibility in information sharing and commenting during the writing process (Parker and Chao 2007), and enabling teachers to monitor students' progress and comment on their writing process more immediately and in greater detail than in non-technologically supported project work (Chu and Kennedy 2011).

Benefits aside, online collaborative writing may appear to students a challenging and demanding task as it may mean an unequal distribution of work, fluctuation in the nature (amount or quality) of participants' contributions (Lipponen et al. 2003), and shallow information processing (Salovaara and Järvelä 2003). Meanwhile, asynchronous collaborative writing can also lack immediate feedback, which is usually available when writing together face to face. During online collaborative writing, the writers are not physically present and thus cannot read 
nonverbal signals, such as facial expressions and gestures that often facilitate interaction in a face to face situation (Kreijns et al. 2003). The absence of nonverbal signals may even prevent collaboration in an online environment.

Interaction between group members is important because it promotes students' knowledge construction during the joint writing process (Erkens and Janssen 2008). Since online collaborative writing is dependent on communication between writers, it is essential to ensure that the co-writers are using the most effective style of interaction (Barile and Durso 2002) in conducting their joint writing process. To enable successful online collaborative writing by ensuring multiple uses of its opportunities and resources, collaborative activities, especially coordination activities are of primary importance.

\section{Collaborative activities during online writing}

Janssen et al. (2012) found in their study on students' collaboration in a computer supported collaborative learning (CSCL) environment that, to work successfully online, students needed to engage in collaborative activities such as performing and coordination activities. Performing activities were related both to the task and to maintaining social relations. Coordination can be defined as "the act of working together harmoniously" (Malone and Crowston 1990, p. 358), or more precisely, "the ability of group members to co-manage their work efforts toward a common goal" (Lowry and Nunamaker 2003, p. 278).

Performing task-related activities relate to acquiring information of all kinds concerning task content. Because their aim was to solve the task at hand, i.e., achieve the best collaborative writing outcome, students had to share their information resources as well as to exchange their ideas and skills (Storch 2005). Performing social activities, in turn, enabled students to maintain a positive group atmosphere (Janssen et al. 2012). Birnholtz et al. (2013) also found that during synchronous collaborative writing in an online chat environment communication was important for upholding social relations, whereas in an asynchronous environment other partners' comments concerning the joint text annoyed participants or were perceived as domineering instructions on how to write correctly. According to Erkens et al. (2005) collaborative learning situation stimulates the processes of coordination one of which is grounding (Janssen et al. 2012). Grounding is related to performing activities because group members have to state information concerning the task in order to collaborate effectively online. To communicate and write collaboratively online students need to ensure they understand each other, thus grounding is an important process for students to establish shared understanding (Janssen et al. 2012).

Janssen et al. (2012) found that, in an online environment, students engaged in coordination of task-related activities, such as planning, monitoring the task process, and evaluation of plans and ideas. Through planning, students could decide on the strategies needed to complete the task and agree on the division of labour. By monitoring, they could assess the amount of time remaining for the task or exchange information important for successful task performance and progress. Evaluation in turn enabled students to review their task process. Janssen et al. (2012) also indicated that collaborative writing online requires coordination of social activities, which means discussion 
of collaborative strategies, monitoring of collaboration processes, and evaluation and reflection on the collaboration process. Janssen et al. (2012) found that groups who emphasized the regulation of collaboration, such as monitoring and evaluating group performance, performed better as a group than those who did not invest in these processes.

\section{Student roles and profiles when writing collaboratively on the web}

An individual participant can assume different roles during collaborative writing. Baecker et al. (1993; see also Posner and Baecker 1992) found four such roles: writer, consultant, reviewer, and editor. The writer transforms ideas into coherent and organized text. The consultant participates actively in the writing process in different stages but does not draft the text. The editor corrects and makes changes to documents written by someone else, and the reviewer comments on the text. In addition, the team leader leads the collaborative writing group through the writing process by planning, rewarding and motivating the others (Lowry et al. 2004). The roles of writers are associated with the division of labour, and often depend on individual participants taking on a certain task. Such actions can be understood as serving co-operation of writers rather than collaboration (Dillenbourg et al. 1996), as in collaborative writing the writers can flexibly exchange their roles (Lowry et al. 2004; Marttunen and Laurinen 2012). For collaborative writing to achieve successful outcomes, the writers involved should be aware of what other group members are doing and what is happening during the writing process (Dourish and Bellotti 1992; Lowry et al. 2004). Awareness information is also important in coordinating collaborative writing (Dourish and Bellotti 1992). The study of profiles, where various roles may be flexibly combined, offers a broader perspective than the study of roles for understanding the complex nature of collaborative writing and the factors involved in the coordination of writing.

Some studies have focused on both writer profiles and writing profiles during a collaborative writing process (Hayes and Flower 1980; van Waes 1992). According to van Waes (1992), writer profiles are profiles specific to an individual writer such as a specific writing style or a specific way of organizing the writing process. Writing profiles, instead, are a set of profiles that describe variations in the organization of writing processes. Hence, writing profiles are not related solely to a person or personal characteristics, but also to the writing task. Profiles may, for example, show how the content of the text is generated, organized and reviewed (Marttunen and Laurinen 2012). In collaborative writing, students' diverse writing profiles must be reconciled with coordination processes. However, students' writing profiles during collaborative writing have not previously been studied from the point of view of coordination.

\section{The present study}

This study examines student profiles related to the coordination processes of collaborative writing. The task assignment included a combination of reading and writing. The students prepared themselves for the collaborative task by reading two chapters 
from their course book (Crain 2005) on developmental theories. The chapters concerned Kohlberg's theory of moral development and Piaget's cognitive developmental theory. After reading the chapters, the students were asked to write an individual summary outlining the main principles of the both theories. The students then discussed their summaries and wrote a joint essay in an online environment. The present research interest was in how university students coordinate their collaborative online writing and what kinds of coordination profiles they show. This study also explores what kinds of combinations of profiles were found in the different writing groups. Furthermore, the study examines the quality of the essays produced by groups containing students with different coordination profiles. The research questions were the following: (1) How do students coordinate their joint writing online? (2) What coordination profiles do students show when writing collaboratively online? (3) Are students' coordination activities associated with the quality of their joint essays? (4) What is the quality of the essays produced by groups comprising different combinations of coordination profiles?

\section{Methods}

\section{Participants}

Participants were twenty-eight Finnish university students (26 females and 2 males; age 20-42 years) enrolled in a course on educational psychology as part of their master's studies. The students were divided into nine groups of 2-4 individuals to perform the collaborative online writing task.

\section{Task assignment}

The learning aim of the course was to acquire knowledge on developmental theories by reading, writing and discussing. Students were asked to perform a writing task, which included working both individually and collaboratively in small groups in a Google Drive environment which is a free web-based word processor allowing users to collaborate online by composing and editing shared documents in real time. Google Drive is readily to be adopted without prior training (Brodahl et al. 2011). To support students in coordinating their online collaborative writing, the teacher created two spaces for each group in Google Drive: a Writing space for collaborative writing and a Planning space to help students to coordinate their collaborative writing. In both spaces, the students could use a word processor for both commenting on and editing shared documents in real time.

\section{Working individually}

The students prepared themselves for the subsequent online work by reading individually two chapters from a course book (Crain 2005; see Table 1). The texts addressed Kohlberg's theory of moral development and Piaget's cognitive 
Table 1 Task assignment

Phases for working

Time

allocated for

working

Working individually

Two weeks

1. Reading book chapters on two developmental theories

2. Listing the key concepts on both theories

3. Adding the concept lists to the Writing space in Google Drive

4. Writing an individual summary on Kohlberg's theory and adding it in the Writing space

Preparing for collaborative writing in Google Drive

Five days

5. Reading summaries by students in one's own group

6. Commenting on and comparing summaries located in the Writing space

Collaborative writing in Google Drive

7. Starting to write a joint essay in the Writing space

8. Using the Planning space during joint writing

9. Searching the Internet for relevant information and incorporating it into the joint essay

10. Revising and completing the joint essay

developmental theory. During reading, the students were asked to list the key concepts of both theories and to clarify those concepts in their own words. After reading, each student was asked to write a short summary including at least three of the central ideas of each theory, and insert both their concept lists and summaries into the Writing space in Google Drive. The students were allowed 2 weeks to read the theories and write their summaries. Before the collaborative online writing, the students read the summaries produced by all the individuals in their own group.

\section{Preparing for collaborative writing}

The students were also asked to comment on and compare each other's summaries in the Writing space by using a comment tool similar to that used in Microsoft Word. In their comments and comparisons, the students were instructed to focus on ideas they found central in both theories.

\section{Collaborative writing in Google Drive}

Based on their concept lists and individual summaries, the students were asked to compose a joint essay on Kohlberg's theory on the stages of moral development. They were free to choose the title for their essay and were given 5 days to complete the task. When composing their joint essay, the students used the Planning space to agree, for example, on the schedule and distribution of work, and the Writing space to plan and compose their joint essay. Each time the students submitted something to the Writing space, they were asked to add into the Planning space a description of what their contribution to the joint essay had been and what they would like the 
other students to contribute to the essay. In addition, the students could comment on the unfinished essay.

The students were also requested to search the Internet for relevant information and insert that information into a suitable place in their joint essay. In this way, the students practiced using the Internet as an information source, both searching for relevant information, and assessing its reliability. When the joint essay was completed, the students were asked to read it through, revise it into its final form, and save the completed essay to the Writing space. The task assignment is illustrated in Table 1.

\section{Data}

The study data consist of 583 comments by students in the Planning space and the students' joint essays $(n=9)$. In this study, the students' comments took the form of written speech turns, including suggestions regarding the distribution of work and the time schedule as well as ideas related to the content of the essays under preparation. Some of the student's comments on content were wide-ranging. It seemed, therefore, reasonable to divide comments of this kind into episodes by topic. Further, many of the students' comments were interactive in nature, meaning that a comment sent by one student would receive comments from other students. By commenting in this dialogical way, the students also maintained social interaction during writing. For the analyses of coordination, it was necessary to unite interactive comments of this kind into episodes. The total number of episodes formed on the basis of the students' comments was 531 (Table 2). Linell (1998) defines an episode as a bounded sequence of comments with a beginning and an end. The episode is the conceptual ensemble, which usually focuses on a discussion about some issue or topic as well as problems. One episode ends and another begins when the focus or topic of the discussion changes (Erkens et al. 2005). The data are described in more detail in Table 2.

Table 2 Study data

\begin{tabular}{lrrrrr}
\hline Group & \multicolumn{2}{l}{ Comments } & & Episodes & $\begin{array}{l}\text { Essays } \\
\text { f (words) }\end{array}$ \\
\cline { 2 - 4 } & \multicolumn{1}{c}{$f$} & $f$ (words) & M (words) & $f$ & f \\
\hline 1 & 36 & 1440 & 40.0 & 99 & 514 \\
2 & 45 & 1493 & 33.2 & 59 & 924 \\
3 & 102 & 1618 & 15.9 & 93 & 819 \\
4 & 37 & 308 & 8.3 & 31 & 754 \\
5 & 32 & 877 & 27.4 & 46 & 1299 \\
6 & 52 & 505 & 9.7 & 31 & 856 \\
7 & 118 & 1398 & 11.8 & 58 & 1004 \\
8 & 121 & 1869 & 15.4 & 84 & 1557 \\
9 & 40 & 529 & 13.2 & 30 & 779 \\
Total & 583 & 10,037 & & 531 & 8506 \\
\hline
\end{tabular}




\section{Data analyses}

\section{Analysis of students' collaborative activities of online writing}

To complete an online collaborative writing task, students have to engage both in performing and coordinating activities. Performing activities are related to task content. By performing task-related activities, students share information and exchange ideas and resources in working towards a common goal (Janssen et al. 2012). Collaborative writing involves social relations between group members. Therefore, students have to perform social activities, e.g. via positive comments and expressions that help to maintain a positive group climate (Janssen et al. 2012). Performing activities can be considered as a part of coordination because of the process of grounding by which the students construct shared understanding and a common frame (Janssen et al. 2012). However, performing activities are not enough to ensure successful online collaborative writing. Janssen et al. (2012) state that collaboration also involves the actual coordination of working such as making plans, monitoring task progress, and evaluating plans and ideas. Moreover, social activities have to be coordinated, meaning that students have to discuss collaboration strategies, monitor the online collaborative writing process, and evaluate the manner in which they collaborate (Janssen et al. 2012).

The episodes related to collaborative activities in the planning space were classified into the following categories used by Janssen et al. (2012): Performing taskrelated activities, Performing social activities, Coordinating task-related activities, and Coordinating social activities. Because the collaborative writing process aims at achieving a joint written product and because the process of writing a text was stressed in the present study, two text-related categories of collaborative activities were added to the analysis: Performing text-related activities, and Coordinating text-related activities. Moreover, because the collaborative writing task was implemented by using an online writing application, a category termed Technical issues was also included. Sometimes students' activities are not all related to the task itself, and thus, the category Off task was also included in the analysis.

Performing activities are aimed at solving the problem at hand, which in the case of collaborative writing means that students work on a shared product, e.g. essay. To do this requires that they pool their information resources and exchange their ideas and opinions (Janssen et al. 2012). The category Performing task-related activities, in turn, includes episodes of information exchange related to the task in general, such as information on the content of the task, information about some student's contribution to the writing space and, in the present instance, information relating to the content of the theories in question. The category Performing text-related activities includes episodes of information exchange focusing on the joint essay itself, for example connecting different parts of the text, revising the text, correcting typos or inserting headings. Finally, the category Performing social activities includes episodes of greetings, friendly comments made to initiate a conversation or positive comments such as thanking a partner for help.

Coordination activities regulate task performance or text progress. The category Coordinating task-related activities involves discussion episodes related to strategies 
necessary to complete the task, such as planning, delegating task responsibilities, managing time and dividing work. Task coordination is also related to information about what is happening right now, for example, assessing the amount of time available and assessing the task or current task progress. The category Coordinating text-related activities encompasses discussion episodes needed to compose a joint essay such as planning and monitoring as well regulating the joint writing process. This category also includes evaluation of the text. Further, the category Coordinating social activities involves episodes of planning how to work together, social regulation and assessment of group performance and collaboration. Some student comments were also related to Technical issues such as problems encountered in writing in the Google Drive environment. Comments unrelated to the task were classified into the category Off task.

Episodes were analysed with the Multiple Episode Protocol Analysis (MEPA) program (Erkens 2005). Interrater reliability (20\% of the total of 193 episodes) by two raters was .69 (Cohen's Kappa). The analytical categories are described in more detail in Table 3.

\section{Analysis of students' joint essays}

The quality of the students' joint essays was assessed by how well the essay met the specific criteria. The students had been asked to write an essay on Kohlberg's stages of moral development by utilizing the course book, searching the Internet and integrating the information from both. Students' joint essays were analysed by applying the task analysis described by Morrison et al. (2007), which includes analysis of the content (e.g. topics) and its structure, such as concepts, procedures and rules. In the present study, the criteria were as follows: the number of topics and the number of concepts included in the essay along with how well the students had integrated Internet sources into their essays. The number of topics was counted to measure how extensively the students had treated Kohlberg's theory. The topics written on included e.g. Description of Kohlberg's method, Six stages of moral development, Implications of the theory for learning and Evaluation of the theory. The maximum number of topics was seven. The number of concepts referred to the number of key concepts related to Kohlberg's theory used by the students in their joint essays. Key concepts were counted by the teacher with help of the course book in which the key concepts were highlighted. The maximum number of key concepts was 61. Integration of Internet sources was analysed according to how the students utilized the information they found on the Internet: whether they simply added the link, copied information or integrated relevant information into their joint essays. Each variable was scored from 1 to 3 points (Table 4). Total scores for essays were calculated by summing the individual variables. The essays were then classified into three quality levels: $3-4$ points $=$ low, $5-6$ points $=$ moderate, $7-9$ points $=$ high.

\section{Statistical analysis}

The associations between the quality of the joint essays and the categories of collaborative activities were analysed by using the nonparametric $\chi^{2}$ test. To describe 

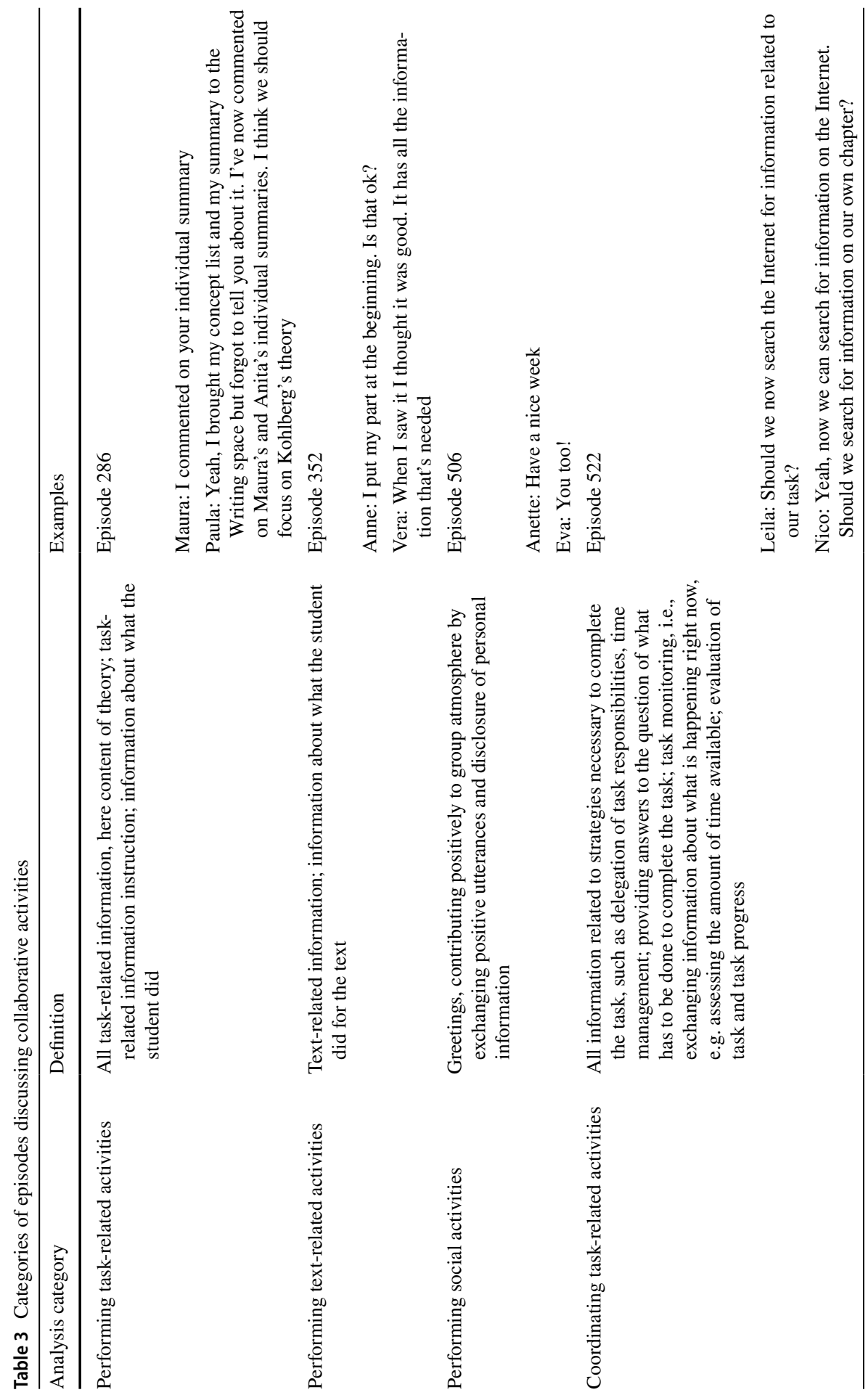

范
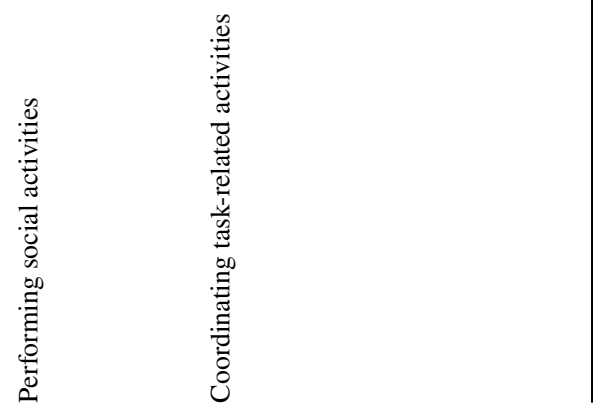


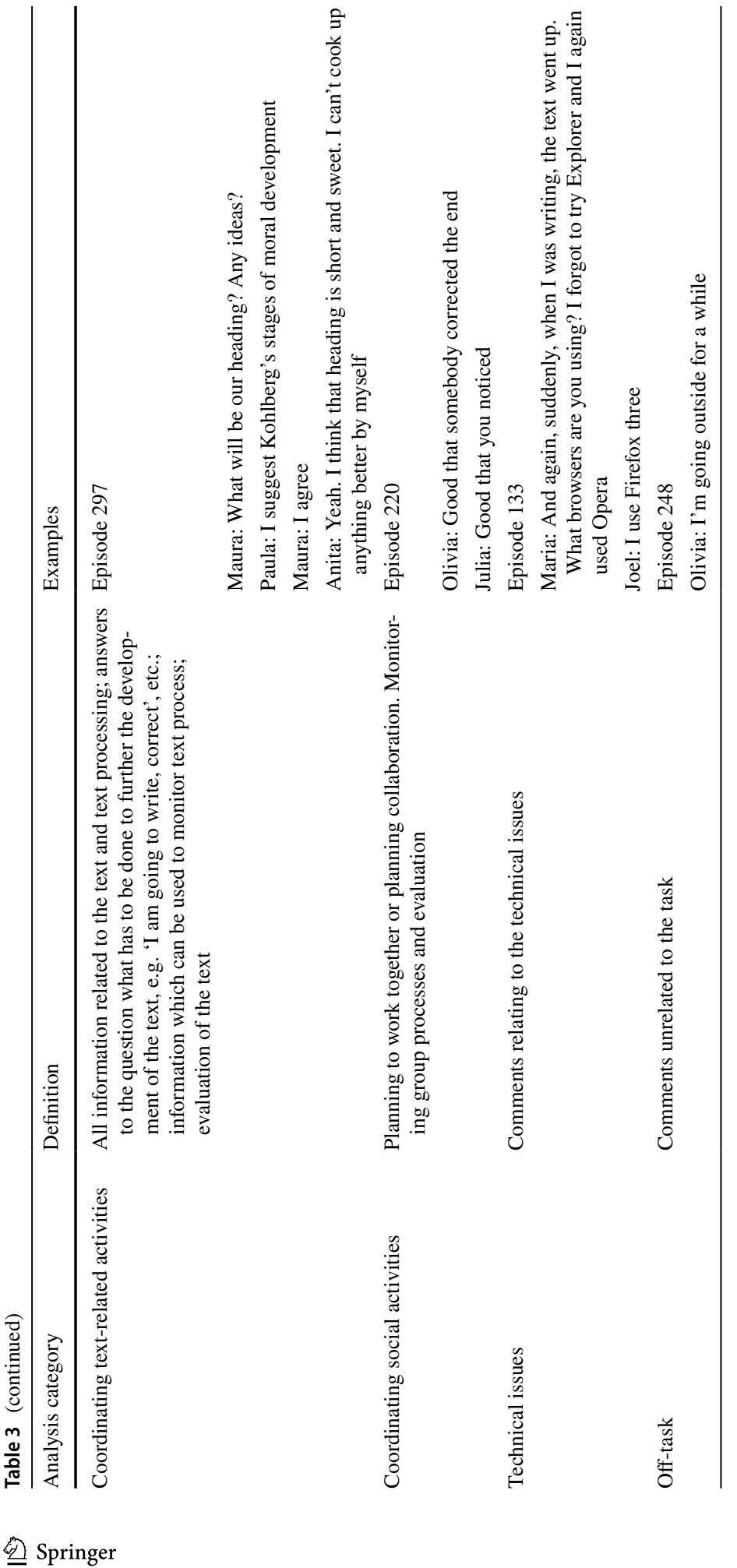


Table 4 The evaluation criteria for the essays

\begin{tabular}{|c|c|c|c|}
\hline \multirow[t]{2}{*}{ Variable } & \multicolumn{3}{|c|}{ Scoring scale of the variables } \\
\hline & 1 point & 2 points & 3 points \\
\hline Number of topics & $0-3$ topics & $4-5$ topics & $6-7$ topics \\
\hline Number of key concepts & $0-20$ concepts & $21-40$ concepts & $41-61$ concepts \\
\hline $\begin{array}{l}\text { Integration of Internet } \\
\text { sources }\end{array}$ & Only a link is added & $\begin{array}{l}\text { Information is copied } \\
\text { directly from the Inter- } \\
\text { net sources }\end{array}$ & $\begin{array}{l}\text { Information from Internet } \\
\text { sources is integrated } \\
\text { into the joint essay }\end{array}$ \\
\hline
\end{tabular}

the nature of the associations found by the $\chi^{2}$ test in greater depth, adjusted residuals were used (Bewick et al. 2004).

To explore the contribution of individual group members to the coordination activities during the collaborative writing process, K-means cluster analysis (Aldenderfer and Blashfield 1984) was used to classify the students into groups with similar characteristics. The idea of cluster analysis is to discover a system of organizing observations, usually people, into groups where members of the groups share properties in common (Stockburger 2016). To facilitate comparability between students' contributions across groups, the proportions of individual students' contributions were used in the analysis. The four-cluster solution with seven collaborative activity variables was used as it best showed the coordination profiles of the students and gave the clearest interpretations of the clusters. Because of the small number of Off-task episodes, this variable was not included in the analysis.

\section{Results}

\section{Students' collaborative activities during online writing}

The students coordinated their collaborative writing mainly through text-related $(24.5 \%)$, task-related $(21.6 \%)$, and social activities (14.5\%). They often performed both task-related $(13.7 \%)$ and text-related activities $(11.9 \%)$. In contrast, episodes on technical issues (7.2\%), performing social activities (5.3\%), and off task activities (1.3\%) were quite rare. The frequencies of episodes related to the different collaborative activities are described in Table 5.

\section{Essay quality}

Each student group composed one essay. Mean essay length was 945 words. The shortest essay was 514 words and the longest 1557 words. On average, the essays contained 5.2 topics, 27.4 key concepts and scored 2.3 for integration of Internet sources. Five essays were assessed as high in quality, three as moderate and one as low in quality (see Table 6). 
Table 5 Distribution of episodes across collaborative activities

\begin{tabular}{lrl}
\hline Episode category (collaborative activity) & \multicolumn{1}{l}{$f$} & $\%$ \\
\hline Coordinating text-related activities & 130 & 24.5 \\
Coordinating task-related activities & 115 & 21.6 \\
Coordinating social activities & 77 & 14.5 \\
Performing task-related activities & 73 & 13.7 \\
Performing text-related activities & 63 & 11.9 \\
Technical issues & 38 & 7.2 \\
Performing social activities & 28 & 5.3 \\
Off-task & 7 & 1.3 \\
Total & 531 & 100 \\
\hline
\end{tabular}

\section{Associations of collaborative activities with essay quality}

There was a significant association between the episodes of students' collaborative activities and the quality of the joint essays $\left(\chi^{2}=26.91 ; d f=14 ; p=.020\right)$. Examination of the standardized residuals (Table 7) shows that the group which produced the low-quality essay performed fewer text-related activities than expected $(f=6,5.9 \%$, $z=-2.0$ ), and often focused on technical issues (usually problems) $(f=16,15.8 \%$, $z=3.8$ ) encountered in the Google Drive environment. The groups which produced the moderate-quality essays focused mostly on coordination of text-related activities although the result was not quite significant $(f=39,29.5 \%, z=1.6)$. The groups which produced high-level essays focused hardly at all on technical issues or problems $(f=12,4.0 \%, z=-3.2)$ and they performed slightly, although not significantly, more task-related activities on coordination $(f=69,23.2 \%, z=0.9)$ than expected.

\section{Students' coordination profiles during collaborative writing}

The collaborative activities cluster analysis yielded four student profiles. These were named as follows: Text-focused task coordinators, Text-focused text coordinators, Task and text coordinators, and Social coordinators facing technical problems. Text-focused task coordinators typically performed text-related activities and concentrated on coordinating task-related activities. In this profile, the mean proportion

Table 6 Essay quality

\begin{tabular}{lcccr}
\hline Variable & \multicolumn{3}{l}{ Quality level of the essays } & \\
\cline { 2 - 5 } & Low $(n=1)$ & Moderate $(n=3)$ & High $(n=5)$ & Total \\
\hline Number of topics $(M)$ & 3.0 & 4.8 & 6.7 & 5.2 \\
Number of key concepts $(M)$ & 19.3 & 27.0 & 54.0 & 27.4 \\
Integration of Internet sources & 1.0 & 2.0 & 3.0 & 2.3 \\
Total scores $(M)$ & 3.0 & 5.6 & 7.6 & 6.4 \\
\hline
\end{tabular}


Table 7 Students' collaborative activities in groups by essay quality

\begin{tabular}{|c|c|c|c|c|c|c|c|c|c|}
\hline \multirow[t]{3}{*}{ Episode category (collaborative activity) } & \multicolumn{9}{|c|}{ Essay quality } \\
\hline & \multicolumn{3}{|c|}{ Low (1 group) } & \multicolumn{3}{|c|}{$\begin{array}{l}\text { Moderate (3 } \\
\text { groups) }\end{array}$} & \multicolumn{3}{|c|}{ High (5 groups) } \\
\hline & $f$ & $\%$ & $z$ & $f$ & $\%$ & $z$ & $f$ & $\%$ & $z$ \\
\hline Performing task-related activities & 10 & 10.0 & -1.2 & 18 & 13.6 & 0.0 & 45 & 15.1 & 1.0 \\
\hline Performing text-related activities & 6 & 5.9 & -2.0 & 20 & 15.2 & 1.3 & 37 & 12.4 & 0.4 \\
\hline Performing social activities & 6 & 5.9 & 0.3 & 4 & 3.0 & -1.3 & 18 & 6.0 & 0.9 \\
\hline Coordinating task-related activities & 21 & 20.8 & -0.2 & 25 & 18.9 & -0.9 & 69 & 23.2 & 0.9 \\
\hline Coordinating text-related activities & 24 & 23.8 & -0.2 & 39 & 29.5 & 1.6 & 67 & 22.5 & -1.2 \\
\hline Coordinating social activities & 17 & 16.8 & 0.7 & 15 & 11.4 & -1.2 & 45 & 15.1 & 0.4 \\
\hline Technical issues & 16 & 15.8 & 3.8 & 10 & 7.6 & 0.2 & 12 & 4.0 & -3.2 \\
\hline Off task & 1 & 1.0 & -0.3 & 1 & 0.8 & -0.7 & 5 & 1.7 & 0.8 \\
\hline Total & 101 & 100 & & 132 & 100 & & 298 & 100 & \\
\hline
\end{tabular}

Significance at the 0.05 level shown in bold

of episodes pertaining to performing text-related activities was 10.2 and that pertaining to coordinating task-related activities was 9.9. Text-focused text coordinators typically focused on producing text. The mean proportion of episodes related to performing text-related activities was 4.4 and that relating to coordinating text-related activities was 4.6. They did not have noteworthy technical problems (2.0). Task and text coordinators mainly coordinated text- (9.4) and task- (7.9) related activities. The Social coordinators facing technical problems profile consisted of students who concentrated a lot on coordinating social activities (6.2) and encountered a lot of technical problems during writing. In this group, the mean proportion of episodes related to technical issues was 14.7. The mean proportions of the different episodes of collaborative activities by the four coordination profiles are presented in Table 8 .

\section{Students' coordination profiles and essay quality}

Most of the writing groups comprised students in the same profile categories (Table 9). Text-focused task coordinators exclusively formed one group (G3), as also did task and text coordinators (G7). Further, text-focused text coordinators exclusively formed groups 4, 5, 6 and 9. Three groups (G1, G2, G8) consisted of students belonging to different profile categories: text-focused text coordinators and social coordinators facing technical problems formed groups G1 and G2, and the text-focused task coordinators and task and text coordinators formed Group 8.

Four of the six groups whose members showed the same coordination profiles, namely groups 3, 6, 7, and 9, composed high-quality essays. The two other groups comprising text-focused text coordinators (groups 4 and 5) composed essays of moderate quality.

The groups containing students from different profile categories and in which the majority were social coordinators facing technical problems (groups 1 and 2) 


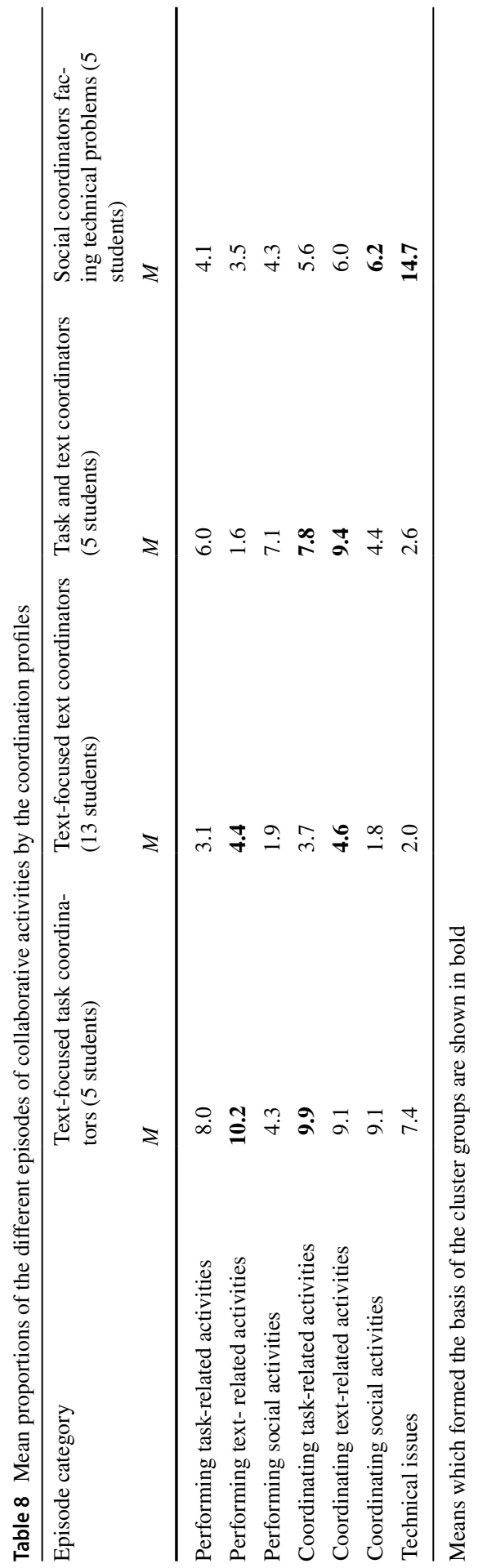


Table 9 Coordination profiles of students comprising the different groups (G1-G9)

\begin{tabular}{lllllllllll}
\hline Profile & G1 & G2 & G3 & G4 & G5 & G6 & G7 & G8 & G9 & Total \\
\hline Text focused task coordinators & 0 & 0 & 3 & 0 & 0 & 0 & 0 & 2 & 0 & 5 \\
Text focused text coordinators & 1 & 1 & 0 & 2 & 3 & 3 & 0 & 0 & 3 & 13 \\
Task and text coordinators & 0 & 0 & 0 & 0 & 0 & 0 & 4 & 1 & 0 & 5 \\
$\quad \begin{array}{l}\text { Social coordinators facing tech- } \\
\quad 3\end{array}$ & 2 & 0 & 0 & 0 & 0 & 0 & 0 & 0 & 5 \\
$\quad$ nical problems & & & & & & & & & & \\
$\quad$ Total & 4 & 3 & 3 & 2 & 3 & 3 & 4 & 3 & 3 & 28 \\
Quality of the essays & L & M & H & M & M & H & H & H & H & \\
\hline
\end{tabular}

$L$ low (3-4 p.), $M$ moderate (5-6 p.), $H$ high (7-8 p.)

composed the lowest quality essays. The third group (group 8) containing students with two different profiles (text-focused task coordinators and text-focused text coordinators), composed an essay of high quality.

\section{Conclusion and discussion}

The students most often coordinated text-related, task-related and social activities when writing collaboratively using Google Drive. The importance of coordination has also been shown in previous studies. For example, Janssen et al. (2012) showed that coordination of social activities, in particular, was a prerequisite for successful group performance: the more students coordinated their social activities the better they performed. Barron (2000) also showed that coordination of group performance is important because it can lead to a better collaborative writing outcome. It was therefore surprising that in the present study only the collaborative activities related to technical issues were most clearly associated with the quality of the students' joint essays (Table 7). The coordination activities showed no significant association with the students' performance. The reason may be that the students were rather homogeneous in their working style; this would explain the small differences in their performance. Technical problems, however, seemed to have a marked effect on the students' collaborative writing performance. The five groups which wrote the high quality essays encountered technical problems significantly less than expected, while the result for the group which produced the low quality essay showed the opposite.

The four coordination profiles identified in this study showed that the students coordinated their online collaborative writing process in different ways. The textfocused text coordinators focused activities related to text production. Some students focused on coordinating both task-related and text-related activities. The difference between these profiles was that whereas the text-focused text coordinators concentrated more frequently on producing the text itself, the task- and text-related coordinators focused slightly more on the task in general. As van Waes (1992) showed, profiles are not related solely to personal characteristics but also to the task directing the writing. Marttunen and Laurinen (2012) suggested that writers' profiles should not be seen as individual properties but as characteristic ways in which writers 
undertake the writing task at hand. Analysis of the associations between essay quality and the students' coordination profiles (Table 9) showed that the text-focused task coordinators, text-focused text coordinators and task and text coordinators composed a moderate- or high-level essay. Moreover, high-level essays were also produced by groups comprising participants with differing profiles. Consequently, it is difficult to generalize about the association between coordination profiles and essay quality.

Technical problems were visible in the students' coordination profiles. The groups containing social coordinators facing technical problems composed essays which were scored slightly lower than those of the other groups. Experiencing technical problems during collaborative writing in an online environment seemed to affect the students' work: these students did not perform task- or text-related activities very often, nor was coordination of task-related activities very common. Veerman and Veldhuis-Diermanse (2001) also showed that technical problems, particularly in synchronous computer mediating communication, can decrease the number of constructive messages and may affect task outcome. It is noteworthy that the present groups with high-level essays did not report technical problems at all; this might have influenced their writing process. Hence, in this study, it is plausible that technical problems might have affected students' motivation to complete the collaborative writing task.

It can be assumed that coordination is needed in a situation where the things are going wrong. If writers encounter problems during their writing task, it can be assumed that the outcome, e.g. the quality of their text, may also remain low. However, in this study, difficulties with the online environment did not promote coordination. On the contrary, it undermined group performance as well as essay quality. It is likely that the nature of the difficulties was so severe that they were not resolvable by coordination, if coordination is understood as the ability of group members to comanage their work efforts toward a common goal by ensuring an equal distribution of the work, managing time and regulating the whole task (Lowry and Nunamaker 2003). Exchanging ideas, planning and monitoring the task process as well as discussing collaborative strategies promote reciprocity between the members of collaborative writing groups. This can facilitate the emergence of real collaboration, which in turn may affect the outcome of the writing process. Moreover, the role of the teacher in guiding students on how to coordinate a task might also promote successful collaboration online.

Some limitations of the study should be considered. The collaborative writing task formed part of the course program, and hence the study design can be considered ecologically valid without the inclusion of a control group. This means, however, that we cannot know whether the online collaborative writing outcomes would have been different for students with no opportunity for preparation. Second, Finnish students of education have largely a similar level of background knowledge. Moreover, preparation through reading and summarizing might have increased this homogeneity of knowledge related to the task. This would help explain the similarity in the ways they worked and hence the only slight variation in essay quality across the groups and the absence of any association between the coordination profiles and essay quality. Third, this study showed that the groups which produced high-level 
essays performed slightly more task-related activities on coordination than the other groups although the result was not quite statistically significant. However, this question should be more clarified in future research. Fourth, the numbers of both the participating groups (9) and participants (28) were small. This may account for the fact that generalizations based on the results cannot be made. More adequate results might have been obtained with larger numbers of groups and participants. The collaborative writing process and its outcomes should therefore be studied in greater depth with larger samples.

To conclude, this study assignment, for which students were amply prepared, was designed to provide them with an opportunity for successful online collaborative writing. Despite its limitations, the study yielded useful information about the online collaborative process in an ecologically valid situation. It clearly revealed what students did and how they coordinated their writing process in an online environment. Coordination profiles have been little studied in connection with collaborative writing tasks. From the pedagogical perspective, collaborative writing in an online environment can be a challenging task. Although Google Drive is ready-to-use software, mastery of it cannot be taken for granted: it should be practiced before embarking on complex collaborative writing tasks. It may be that teachers should participate more actively in the online collaborative writing process to help with technical problems as these arise.

Acknowledgements Open access funding provided by University of Jyväskylä (JYU). The authors thank Michael Freeman for his valuable comments on the language.

\section{Compliance with ethical standards}

Conflict of interest The authors declare that they have no conflict of interest.

Ethical approval All procedures performed in studies involving human participants were in accordance with the ethical standards of the institutional and/or national research committee and with the 1964 Helsinki declaration and its later amendments or comparable ethical standards.

Open Access This article is distributed under the terms of the Creative Commons Attribution 4.0 International License (http://creativecommons.org/licenses/by/4.0/), which permits unrestricted use, distribution, and reproduction in any medium, provided you give appropriate credit to the original author(s) and the source, provide a link to the Creative Commons license, and indicate if changes were made.

\section{References}

Aldenderfer, M. S., \& Blashfield, R. K. (1984). Cluster analysis. Sage University Paper Series, No. 07044. Beverly Hills, CA: Sage.

Alexander, B. (2006). Web 2.0: A new wave of innovation for teaching and learning? EDUCAUSE Review, 41(2), 32-44.

Baecker, R. M., Nastos, D., Posner, I. R., \& Mawby, K. L. (1993). The user-centred iterative design of collaborative writing software. In Proceedings of the INTERACT'93 and CHI'93 conference on human factors in computer systems, Amsterdam, The Netherlands (pp. 399-405). https://doi. org/10.1145/169059.169312. 
Barile, A. L., \& Durso, F. T. (2002). Computer-mediated communication in collaborative writing. Computers in Human Behavior, 18(2), 173-190. https://doi.org/10.1016/S0747-5632(01)00040-1.

Barron, B. (2000). Achieving coordination in collaborative problem-solving groups. Journal of the Learning Sciences, 9(4), 403-436. https://doi.org/10.1207/S15327809JLS0904_2.

Bewick, V., Cheek, L., \& Ball, J. (2004). Statistics review 8: Qualitative data-test of association. Critical Care, 8, 46-53. https://doi.org/10.1186/cc2428.

Birnholtz, J., Steinhardt, S. B., \& Pavese, A. (2013). Write here, write now! An experimental study of group maintenance in collaborative writing. In Proceedings of the SIGCHI'13 conference on human factors in computing systems, Paris, France (pp. 961-970). https://doi.org/10.1145/2470654.24661 23.

Brodahl, C., Hadjerrouit, S., \& Hansen, N. K. (2011) Collaborative writing with web 2.0 technologies: Education students' perceptions. Journal of Information Technology Education, 10, IIP73-IIP103. Retrieved from http://jite.org/documents/Vol10/JITEv10IIPp073-103Brodah1948.pdf. Accessed 21 Jun 2018.

Chu, S. K.-W., \& Kennedy, D. M. (2011). Using online collaborative tools for groups to co-construct knowledge. Online Information Review, 35(4), 581-597. https://doi.org/10.1108/146845211111619 45.

Crain, W. (2005). Theories of development: Concepts and applications. Upper Saddle River, NJ: Pearson/ Prentice Hall.

Dillenbourg, P., Baker, M., Blaye, A., \& O’Malley, C. (1996). The evolution of research on collaborative learning. In E. Spada \& P. Reiman (Eds.), Learning in humans and machine: Towards an interdisciplinary learning science (pp. 189-211). Oxford: Elsevier.

Dourish, P., \& Bellotti, V. (1992). Awareness and coordination in shared workspaces. In Proceedings of the 1992 ACM conference on computer-supported cooperative work, Canada (pp. 104-144). https:// doi.org/10.1145/143457.143468.

Erkens, G. (2005). Multiple episode protocol analysis (MEPA). Version 4.10. Utrecht: Utrecht University.

Erkens, G., \& Janssen, J. (2008). Automatic coding of dialogue acts in collaboration protocols. International Journal of Computer-Supported Collaborative Learning, 3(4), 447-470. https://doi. org/10.1007/s11412-008-9052-6.

Erkens, G., Jaspers, J., Prangsma, M., \& Kanselaar, G. (2005). Coordination processes in computer supported collaborative writing. Computers in Human Behavior, 21(3), 463-486. https://doi. org/10.1016/j.chb.2004.10.038.

Giroud, A. (1999). Studying argumentative text processing through collaborative writing. In J. Andriessen \& P. Coirier (Eds.), Foundations of argumentative text processing (pp. 149-178). Amsterdam: Amsterdam University Press.

Hayes, J. R., \& Flower, L. S. (1980). Identifying the organization of writing processes. In L. W. Gregg \& E. R. Steinberg (Eds.), Cognitive processes in writing (pp. 3-30). Hillsdale, NJ: Lawrence Erlbaum Associates.

Janssen, J., Erkens, G., Kirschner, P. A., \& Kanselaar, G. (2012). Task-related and social regulation during online collaborative learning. Metacognition and Learning, 7(1), 25-43. https://doi.org/10.1007/ s11409-010-9061-5.

Kreijns, K., Kirschner, P. A., \& Jochems, W. (2003). Identifying the pitfalls for social interaction in computer-supported collaborative learning environments: A review of the research. Computers in Human Behavior, 19(3), 335-353. https://doi.org/10.1016/S0747-5632(02)00057-2.

Linell, P. (1998). Approaching dialogue: Talk, interaction and contexts in dialogical perspectives. Amsterdam: John Benjamins.

Lipponen, L., Rahikainen, M., Lallimo, J., \& Hakkarainen, K. (2003). Patterns of participation and discourse in elementary students' computer supported collaborative learning. Learning and Instruction, 13(5), 487-509. https://doi.org/10.1016/S0959-4752(02)00042-7.

Lowry, P. B., Curtis, A., \& Lowry, M. R. (2004). Building a taxonomy and nomenclature of collaborative writing to improve interdisciplinary research and practice. Journal of Business Communication, 41(1), 66-99. https://doi.org/10.1177/0021943603259363.

Lowry, P. B., \& Nunamaker, J. F., Jr. (2003). Using Internet-based distributed collaborative writing tools to improve coordination and group awareness in writing teams. IEEE Transactions on Professional Communication, 46(4), 277-297. https://doi.org/10.1109/TPC.2003.819640.

Malone, T. W., \& Crowston, K. (1990). What is coordination theory and how can it help design cooperative work systems? In Proceedings of the 1990 ACM conference on computer-supported cooperative 
work (CSCW'90), Los Angeles, California, USA (pp. 357-370). https://doi.org/10.1145/99332 .99367.

Marttunen, M., \& Laurinen, L. (2012). Participant profiles during collaborative writing. Journal of Writing Research, 4(1), 53-79.

Morrison, G. R., Ross, S. M., \& Kemp, J. E. (2007). Designing effective instruction. Hoboken, NJ: Wiley.

Murugesan, S. (2007). Understanding Web 2.0. IT Professional, 9(4), 34-41. https://doi.org/10.1109/ MITP.2007.78.

Parker, K. R., \& Chao, J. T. (2007). Wiki as a teaching tool. Interdisciplinary Journal of Knowledge and Learning Objects, 3, 57-72.

Posner, I. R., \& Baecker, R. M. (1992). How people write together. In Proceedings of the twenty-fifth Hawaii international conference on system sciences, Honolulu, HI, USA (pp. 127-138).

Salovaara, H., \& Järvelä, S. (2003). Students' strategic actions in computer-supported collaborative learning. Learning Environments Research, 6(3), 267-285. https://doi.org/10.1023/A:1027379824485.

Stockburger, D. W. (2016). Multivariate statistics: concepts, models, and applications. 3rd Web edition. Missouri State University. Retrieved from http://psychstat3.missouristate.edu/Documents/Multi Book3/mbk.htm. Accessed 26 Jun 2018.

Storch, N. (2005). Collaborative writing: Product, process and students' reflections. Journal of Second Language Writing, 14(3), 153-173. https://doi.org/10.1016/j.jslw.2005.05.002.

Van Waes, L. (1992). The influence of the computer on writing profiles. In H. Pander Maat \& M. Steehouder (Eds.), Studies of functional text quality (pp. 173-187). Amsterdam: Rodopi.

Veerman, A., \& Veldhuis-Diermanse, E. (2001). Collaborative learning through computer-mediated communication in academic education. In Proceedings European perspectives on computer supported collaborative learning: Euro-CSCL (pp. 625-632). Maastricht.
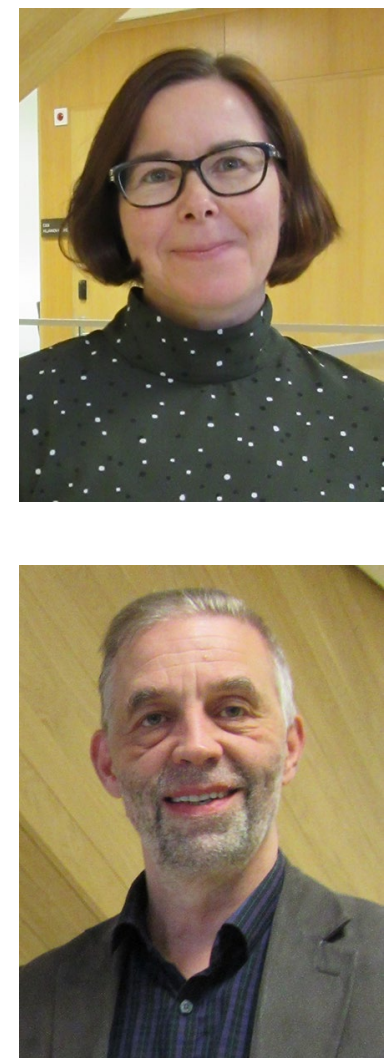

Minna Nykopp is a PhD Student at the Department of Education, University of Jyväskylä, Finland. Her research interests are collaborative writing and its meaning for learning.

Miika Marttunen is a Professor of Education at the Department of Education in the University of Jyväskylä, Finland. His research interests include argumentation, digital literacies, online learning, collaborative learning, and collaborative writing. 


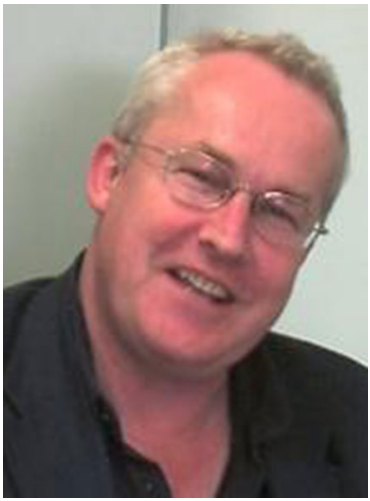

Gijsbert Erkens is a retired Associate Professor in Educational Psychology at the Department of Education of the Utrecht University in the Netherlands. His research interests are computer supported collaborative learning (CSCL) and argumentative writing and discussion. 